\title{
A OVELHA NÃO FOGE PORQUE 0 LOBO NÃO É BELO, MAS PORQUE É SEU INIMIGO NATURAL: OS FRACASSOS DE KANT E AS FRONTEIRAS ENTRE 0 ESTÉTICO E 0 METAFÍSICO-RELIGIOSO
}

\section{Arthur Grupillo ${ }^{1}$}

\section{RESUMO}

Acreditamos que Kant se equivocou na dedução do princípio de universalidade do que é produzido no simples ajuizamento, cujo paradigma é o juízo de gosto puro, sobre o belo. Isto é, Kant não consegue provar, com um argumento transcendental, o direito de pressupor a priori um "sentido comum" (sensus communis), e com ele a possibilidade de uma validade universal intersubjetiva não-objetiva. Mas, parece, o fracasso de Kant é mais iluminador do que teria sido seu "sucesso". O tipo de princípio que ele realmente procurava tem, na verdade, uma longa história. Encontramos indicações bastante instrutivas na psicologia do animal perfeito elaborada por São Tomás de Aquino (por exemplo, Suma Teológica I, q.78, a.4 e Questões Disputadas sobre a Alma, q. XIII), mas que merecem ajustes diante de sua vasta e complexa filosofia. Algumas características da abordagem tomista podem ajudar a entender porque o sensus communis não poderia ser deduzido por uma prova idealista, baseada na objetividade do conhecimento, mas somente numa "prova realista", que parte da complexidade observada dos fenômenos naturais e psíquicos, no homem quanto em outros animais.

Palavras-chave: Estética; Metafísica; Kant; Tomás de Aquino; Sensus communis.

\section{ABSTRACT}

We believe that Kant was wrong in his attempt to deduce the principle of universality of what is produced in simple judgment, whose paradigm is pure aesthetic judgment of the beautiful. That is, Kant is not able to prove with a transcendental argument the right to presuppose a priori a "common sense" (sensus communis) and thereby the possibility of an intersubjective, non-objective validity. But, it seems that Kant's failure is more enlightening than his "achievement". The kind of principle that he was really searching for, as a matter of fact, has a long history. We find quite instructive indications in the psychology of the perfect animal developed by St. Thomas Aquinas (for instance, in the Summa Theologica I, q.78, a.4 and in the Disputed Questions on the Soul q. XIII). However, these indications need to be adjusted in view of

\footnotetext{
${ }^{1}$ Doutor em Filosofia. Professor do Programa de Pós-graduação em Filosofia e do curso de filosofia da Universidade Federal de Sergipe. E-mail: aegrupillo@gmail.com
} 
Aquinas's vast and complex philosophy. Some characteristics of the Thomist approach can be helpful to understand why sensus communis could not be deduced by an idealist proof, based on the objectivity of knowledge, but rather only by a "realist proof", which starts from the observed complexity of natural and psychic phenomena, both in humans as well as in other animals.

Keywords: Aesthetics; Metaphysics; Kant, Thomas Aquinas; Sensus communis.

\section{Introdução}

A Crítica da Faculdade do Juízo tem sido objeto das mais variadas interpretações e apropriações. Não há melhor explicação desta possibilidade a não ser por uma instabilidade interna, objetiva, da própria obra. Aqueles que se debruçaram sobre ela à maneira de um comentador moderno, nela perceberam vários equívocos, e ficaram, sobre questões estéticas, com um gosto cético na boca (Cf. GUYER, 1997; MACMILLAN, 1985; GRUPILLO, 2016). Outros, mais dogmáticos, passam rapidamente pelos equívocos, apontando-os apenas para mostrar que, em alguma outra parte da filosofia de Kant, "deve" haver uma solução (cf. ALLISON, 2001). Pois sempre se pode recorrer à distinção fichteana, herdada dos escritos paulinos, entre a letra e o espírito de uma filosofia, no caso a de Kant, para aproveitar seus problemas como ocasiões de aperfeiçoamento e desenvolvimento, em vez de optar pela solução fácil, embora não ilegítima, da mera recusa. Mas mesmo Fichte e Schiller, por exemplo, não estavam de acordo sobre qual era a letra e qual o espírito do pensamento de Kant. Enquanto Schiller afirmava que enxergar a sensibilidade como "empecilho" que obstrui o caminho à razão pode até estar na letra, mas não no espírito de uma filosofia transcendental, Fichte pensava exatamente o inverso, que esta ideia poderia não estar na letra, mas certamente estava no espírito daquela filosofia ${ }^{2}$.

Utilizarei aqui um método distinto, nem tanto para simples "refutação" de alguns argumentos presentes na terceira Crítica, nem tampouco para salvaguardar o espírito da filosofia de Kant, ainda que às custas de sua própria letra. Sem dúvida, gostaria de aprender com os erros e tentar, se possível, tomar o caminho da busca de solução antes que do ceticismo. Mas não tenho

\footnotetext{
2 Sobre essa controvérsia entre Schiller e Fichte, conferir a "Introdução" escrita por Ulisses Razzante Vaccari à sua tradução da obra de Fichte, Sobre o espírito e a letra na filosofia. São Paulo: Humanitas/Imprensa Oficial do Estado de São Paulo, 2014.
} 
nenhum compromisso a priori de que essa solução deva ser encontrada em alguma outra parte da filosofia de Kant. Tem um significado mais histórico do que filosófico o fato de que, quando Jacobi denunciou tão claramente a problemática da coisa em si em Kant, no Apêndice a seu livro David Hume sobre a crença on Idealismo e Realismo, e mostrou a necessidade de reconsiderar o realismo, a maior parte dos filósofos hoje conhecidos optaram como solução radicalizar ainda mais o idealismo, até torná-lo absoluto. Mas, posteriormente, Jacobi considerou que a contradição no sistema kantiano não significava nem uma mera refutação nem uma oportunidade de salvar seu espírito, mas demonstrava "a probidade humana do filósofo de Koenigsberg"’3. Era o sintoma objetivo de que algum sentido realista se impunha ou resistia ao esforço idealista transcendental. ${ }^{4}$

Mais que um compromisso com o espírito da filosofia de Kant, creio ser preciso um compromisso com o espírito da filosofia ou, mais ainda, com uma tal probidade. E é precisamente isto o que mais parece significativo nos equívocos de Kant que estudaremos a seguir: que não é tanto que eles erram na letra mas podem ser resgatados no espírito, mas que eles erram na letra tanto quanto no espírito, mas podem ser resgatados no espírito da filosofia, pura e simplesmente. Aquilo que não está na letra nem no espírito da filosofia transcendental, mas está presente em Kant como filósofo, isto é, como alguém que é obrigado a render-se à objetividade de um conceito às custas não só de sua letra, mas às vezes também de seu próprio espírito, é o que buscamos. No mesmo sentido de Jacobi, acreditamos ver Kant filosofando à revelia de si mesmo, como que cometendo "atos falhos" filosóficos, o que gostaríamos de apontar à luz desta intrigante sugestão do filósofo moral inglês G.E. Moore:

\footnotetext{
${ }^{3}$ Nas luminosas palavras de Manuel Carmo Ferreira: “A evolução de Jacobi, expressa no juízo «o que me separa da doutrina kantiana é somente o que a separa de si mesma» (Werke II, 29) atenua a denúncia acerca da inconsequência kantiana para sublinhar que a manutenção da contradição no sistema prova a probidade humana do filósofo de Koenigsberg: sendo o criticismo, tendencialmente, um idealismo integral (Universal-Idealismus, Werke II, 38, 41) e um niilismo que se confunde com um subjetivismo total, a distinção mantida entre fenômeno e coisa em si testemunha uma fidelidade ao realismo que supõe a subsistência em si do mundo e que afirma Deus, a imortalidade da alma e a liberdade como caução inabalável da ordem prática, mesmo se reduzidos a ficções heurísticas no plano teorético" (FERREIRA, 1992).

${ }^{4}$ Foi o que, mais tarde, Schelling procurou mostrar nas suas Cartas filosóficas sobre o dogmatismo e o criticismo, enfatizando que as duas perspectivas são igualmente legítimas (e ilegítimas) em filosofia, pois remetem uma à outra e se anulam. Isto que para Schelling constituía, portanto, a exigência de uma filosofia do absoluto, já continha, pela crítica ao criticismo anunciada, o embrião de sua posterior filosofia positiva. (Cf. SCHELLING, 1980; 2014).
} 
"A inclusão de provas irrelevantes costuma indicar que o filósofo estava pensando não na questão à qual pretendia responder, mas em outra qualquer, totalmente diferente" (1999, p. 75).

\section{Se se pode com razão pressupor um sentido comum}

Ao final da exposição dos juízos estéticos puros na Analítica do Belo da CFJ, Kant reunifica as condições formais de possibilidade de um juízo com as características analisadas (desinteressado, segundo a qualidade; universal, segundo a quantidade do sujeito da enunciação, não do enunciado; conformea-fins-sem-fim, segundo a relação; e exemplarmente necessário, segundo a modalidade) no conceito de um sentido comum (sensus communis):

Portanto, somente sob a pressuposição de que haja (es gebe) um sentido comum (pelo qual, porém, não entendemos nenhum sentido externo, mas o efeito decorrente do livre jogo de nossas faculdades de conhecimento), somente sob a pressuposição, digo eu, de um tal sentido comum o juízo de gosto pode ser proferido" (CFJ, 83-4)5.

Sob essa pressuposição, então, a conexão expressa num juízo de gosto é representada como objetiva, embora seja apenas subjetiva. Isto é, não encontrando fundamento de determinação do juízo em seu interesse particular, o que prova ser um juízo de gosto puro logicamente possivel, o juízo apenas subjetivo, ao pressupor uma faculdade de sentir idêntica em cada um (o sentido comum), pode ser dito também realmente possivel, de acordo com as condições de uso da faculdade de julgar em geral. Daí o título emblemático do $\$ 22$ : “A necessidade do assentimento universal, que é pensada em um juízo de gosto, é uma necessidade subjetiva, que sob a pressuposição de um sentido comum (sensus communis) é representada como objetiva". Daí também a exigência forte de uma dedução transcendental de que "haja" um tal sentido comum. Entretanto, não é preciso onerar tal noção equiparando-a à de existência empírica, embora seja, de fato, o pressuposto de uma existência. Não se trata de um sentido comum psicológico-naturalista, pois, de acordo com o ponto de vista do idealismo transcendental, "existe" o que está realmente, e não

\footnotetext{
${ }^{5}$ Utilizaremos, às vezes modificada, a tradução luso-brasileira Crítica da Faculdade do Juízo. Rio de Janeiro: Forense Universitária, 1995. Daqui em diante citada apenas como CFJ, seguida da paginação desta edição. Todas as citações foram confrontadas com o original, na edição da Academia. KANT, I. Kritik der Urteilskraft. In: Immanuel Kants Werke, v.5, AkademieTextausgabe. Berlin: Walter de Gruyter \& Co., 1968.
} 
apenas logicamente, de acordo com as condições transcendentais de possibilidade da experiência, e sobre esta realidade ideal se funda a necessidade e a universalidade. Um sentido comum "empírico" não poderia fundar nenhuma das duas. Uma existência empírica é apenas empiricamente real, mas a possibilidade real de acordo com as condições ideais da experiência é o que sustenta o conceito de uma realidade objetiva, não apenas empírica, pensada do ponto de vista de um idealismo ou subjetivismo transcendental.

Também não é necessário, aqui, repetir as reiteradas críticas feitas ao texto kantiano que pretende prover o sentido comum de uma dedução transcendental. Sobretudo a tentativa esboçada no $\$ 21$ sofre de uma falácia lógica elementar, já identificada por vários intérpretes (cf. GUYER, 1997, p. 255 passim; MACMILLAN, 1985; GRUPILLO, 2016, p. 92 passim). Dito de modo bastante sumário, Kant afirma que se o conhecimento é universalmente comunicável, então o estado de ânimo que é condição do conhecimento também deve sê-lo, o que é tão convincente quanto dizer que se a água é líquida e inodora, então o hidrogênio que é condição da água também deve sêlo. Neste caso, há a interferência de outra condição, o oxigênio. O princípio valeria se a água fosse feita apenas de hidrogênio, o que significa que o argumento de Kant teria validade se o conhecimento apenas fosse constituído de seu estado de ânimo, mas nele ocorre a interferência de outras condições, como um conceito do objeto, por exemplo. Por isso, não é possível afirmar com segurança se a comunicabilidade do conhecimento se deve às suas condições subjetivas ou objetivas. É sintomático, diante deste "fracasso" da dedução do $\$ 21$, que o parágrafo seguinte se coloque a pergunta de se o sentido comum é um princípio constitutivo do gosto ou apenas regulativo, cuja regra indeterminada conclama ao cultivo desta faculdade mais que ao direito de ajuizar com pretensão de universalidade e necessidade.

Mas esta falácia elementar não é plena de significado filosófico. Ela tem um interesse ou alcance restrito. $\mathrm{O}$ mesmo acontece com parte do argumento que comete a mesma falácia no $\$ 38$. Esses problemas de ordem formal-lógica na argumentação de Kant são, dizemos, insuspeitos ou de restrita relevância metafísica. Há, contudo, outros dois problemas mais específicos na tentativa de dedução do sentido comum, que ocorrem também no $\$ 21$ e $₫ 38$, assim como 
na "Observação" e numa nota de rodapé que segue este último. São eles, respectivamente, o problema do emprego linguístico do termo "belo" e o que denominamos de "problema da subsunção". Estes são deveras suspeitos e de ampla relevância metafísica, acreditamos. Principalmente porque, embora mais específicos, revelam uma característica comum de importante significado filosófico: a circularidade.

\subsection{O emprego do termo "belo" e o método de Kant-primeira circularidade}

É particularmente intrigante que Kant pretenda derivar a universalidade do belo, analiticamente, de seu desinteresse, invertendo a ordem de exposição do momento da quantidade sobre o momento da qualidade característica da Crítica da Rããa Pura. Porém, logo em seguida, insiste sobre a "curiosidade" [Merkwürdigkeit] da universalidade do gosto puro não para o lógico, mas para o filósofo transcendental (CFJ, 58). Pois não se trata da universalidade do sujeito lógico do enunciado ["Todos os cavalos árabes são belos", por exemplo], mas da universalidade vinculada no juízo a todo sujeito capaz de julgar, isto é, da “validade para cada um”, que é um problema para o filósofo transcendental. Mas, como sabemos, o filósofo transcendental entra em cena apenas para a demonstração da realidade objetiva de certos usos que fazemos de determinados conceitos. No caso da primeira Crítica, conceitos como o de causalidade ou de Deus, entre outros. Mas, aqui, não é verdadeiramente o conceito de universalidade que está em jogo, pois todo juízo de gosto puro é, com efeito, singular [Rasul (este cavalo árabe) é belo], e sim o conceito de uma "validade universal não objetiva" ou "comprazimento universal sem conceito" (CFJ, \6), que deriva diretamente da distinção linguística entre agradável, bom e belo. Daí que ele afirme, no início do $\$ 8$, que “esta reivindicação de validade universal pertence tão essencialmente a um juízo pelo qual declaramos algo belo, que sem pensar essa universalidade ninguém teria ideia de usar essa expressão" (CFJ, 58).

Podemos dizer, então, que é uma curiosidade para o filósofo transcendental, não para o lógico, que empreguemos o termo belo de um determinado modo, a saber, o que exige universalidade para cada um, sem explicação, isto é, sem conceito. O filósofo precisa demonstrar a realidade objetiva desta ideia: universalidade sem conceito, implícita no emprego 
linguístico do termo "belo". Ora, sabemos que Kant foi um crítico perspicaz da tentativa de demonstrar a realidade objetiva de nosso discurso sobre o mundo utilizando-se apenas de princípios lógico-formais, à maneira de Wolff e Leibniz, o que à primeira vista, de fato, parece impossível, e pretendeu demonstrar, antes, como determinados conceitos possuíam realidade objetiva na medida em que dispunham uma determinada lógica da experiência, que não necessariamente contrariava a lógica formal. Por exemplo, é impossível experimentarmos um fenômeno cujo efeito se dê antes da causa. Nem experimentarmos um fenômeno sem causa. Por esta razão, a realidade objetiva do conceito de causalidade não se demonstra por silogismo, mas por argumento transcendental.

Mas, para isso, Kant precisava sempre de partir de um determinado uso que fazemos de conceitos, a fim de verificar se neles estavam apoiadas certas condições de possibilidade de nossa experiência do mundo, provando assim sua realidade objetiva. Ele não parte de princípios formais, mas de princípios materiais herdados da linguagem comum. Como, por exemplo, na Fundamentação da Metafísica dos Costumes, em que parte de uma "filosofia moral popular" para só então fazer a "transição" para a Crítica da Raz̧ão Prática. E mesmo nesta estão assumidas distinções conceituais, repetidas na última Crítica, que na verdade são fatos sobre a linguagem comum:

(...) deste modo o conceito do que é imediatamente bom remeteria somente àquilo com que a sensação de deleite está imediatamente vinculada, e o conceito do simplesmente mau teria de referir-se unicamente àquilo que provoca imediatamente dor. Mas porque isto já contraria o uso linguístico, que distingue o agradável do bom, e o desagradável do mau, e exige que bom e mau sejam sempre ajuizados pela razão, por conseguinte, mediante conceitos que se deixam comunicar universalmente e não mediante simples sensação (...), o ajuizamento da relação dos meios a fins pertence indubitavelmente à razão (KANT, 2002, p.94 [A 102]).

A distinção entre bom/mau e agradável/desagradável é uma distinção que importa ao filósofo transcendental, pois está em questão aí quais conceitos, i.e., quais empregos, demandam justificação de sua realidade objetiva. Não se trata de uma questão lógica, mas de um problema da objetividade de um discurso sobre o mundo, seja um discurso teórico, moral ou estético. Por isso, o ponto 
de partida não pode ser conceitual, pois revirando logicamente conceitos, com auxílio dos princípios lógicos de identidade e não-contradição, não consigo "sair", mediante um termo médio, da esfera do próprio discurso para aquela da objetividade do discurso, que importa provar. Disto Kant já estava consciente às vésperas do período crítico, quando explicou a necessidade de tomar como certos, ainda que de modo provisório, alguns "princípios materiais", contanto que parecessem evidentes para "todo entendimento humano":

\begin{abstract}
Partindo apenas dos princípios formais não podemos demonstrar absolutamente nada, pois que são requeridas proposições que contenham o termo médio graças ao qual a relação lógica dos outros conceitos deve poder ser conhecida num silogismo e, entre estas proposições, algumas devem ser primeiras. Contudo, só podemos conceder a certas proposições o valor de princípios materiais supremos se parecem evidentes [angenscheinlich] para todo o entendimento humano [jeden menschlichen Verstand] (KANT, 1983 p. 151).
\end{abstract}

Falta à última citação a expressão típica "entendimento humano comum", restando sua expressão correlata "todo" entendimento humano. Mas é a ela, em último caso, que se referem tais "princípios materiais", na medida em que possuem fundamento provisório, impossível de demonstração formal, apoiado num "sentimento de convicção" [Gefühl der Überzeugung]. Um fundamento, portanto, referido ao sujeito, e não ao objeto, o que mostra já o caráter bastante "crítico" deste texto pré-crítico, ou pelo menos seu caráter fronteiriço. Afirma-se algo que a Crítica jamais aprovaria, a ideia de "conhecimentos indemonstráveis" [unerweisliche Erkenntisse], mas seu fundamento não possui aquele caráter dogmático de um realismo linguístico do entendimento humano comum: "Ora, há realmente muitos conhecimentos indemonstráveis; sozinho, o sentimento de convicção em relação a isso é uma confissão, mas que não é uma prova da sua verdade" (ibid., p.152 - tradução modificada). O conceito de convicção, por sua vez, é explicado, no Cânone da Razão Pura da Doutrina Transcendental do Método, enquanto fundamento subjetivo da crença que, embora possa "repousar sobre princípios objetivos", "também exige causas subjetivas no espírito do que julga" (CRP A 820/B 
$848)^{6}$, caracterizando em grande medida o que Kant tomará por um sensus communis logicus que, entretanto, não é idêntico ao estético?

Ao juízo estético, contudo, está ligado um sentimento de convicção que seria o mesmo que deve acompanhar todo juízo, sobretudo o de conhecimento, o que, aliás, Kant pressupõe como parte da dedução levada adiante no \$21. O estado de ânimo que, sendo condição necessária do conhecimento, deve poder, assim como o próprio conhecimento, ser comunicado universalmente, é o mesmo sentimento de convicção que, se bem que na ausência de conceitos, acompanha também, como condição suficiente, o juízo de gosto puro. Eis o que pretende fazer ver, ainda que falaciosamente, a primeira tentativa de dedução:

Conhecimentos e juízos, juntamente com a convicção [Überzengung] que os acompanha, têm que poder comunicarse universalmente; pois, do contrário, eles não alcançariam nenhuma concordância com o objeto; eles seriam em suma um jogo simplesmente subjetivo das faculdades de representação, precisamente como o ceticismo o reclama. Se, porém, conhecimentos devem poder comunicar-se, então também o estado de ânimo, isto é, a disposição das faculdades de conhecimento para um conhecimento em geral, e na verdade aquela proporção que se presta a uma representação (pela qual um objeto nos é dado) para fazê-la um conhecimento, tem que poder comunicar-se universalmente; porque sem esta condição subjetiva do conhecer, o conhecimento como efeito não poderia surgir (CFJ, 84).

A circularidade, que já se pode entrever, constitui-se da seguinte maneira. Ninguém teria, para Kant, a ideia de empregar o termo "belo" sem pretensão de universalidade, e isto é um princípio material do entendimento comum, cujo fundamento subjetivo é uma espécie de sentimento de convicção. Mas o belo é objeto de um juízo fundado sobre uma espécie de sentido comum, que é um sentimento de convicção sem ligação com conceitos. Logo, é um princípio material do entendimento humano comum (sensus communis logicus) que o belo, na medida em que é objeto de um juízo fundado sobre uma

\footnotetext{
${ }^{6}$ Utilizaremos, às vezes modificada, a tradução portuguesa de Manuela Pinto dos Santos e Alexandre Fradique Morujão: Crítica da Razão Pura. Lisboa: Fundação Calouste Gulbenkian, 2001. Cada citação sempre confrontada com o original, com a paginação comum para as edições A(1781) e B(1787).

7 "Pode-se designar o gosto como sensus communis aestheticus e o entendimento humano comum como sensus communis logicus." (CFJ, 142 Nota 156)
} 
espécie de sentido comum (sensus communis aestheticus), não pode ser empregado corretamente sem pretensão de universalidade.

O emprego do termo "belo" ligado à universalidade serve como ponto de partida de uma argumentação que quer fornecer uma prova objetiva para a validade universal (não objetiva) do belo. É como se eu partisse de conhecimentos indemonstráveis, de que estou convicto, para construir uma prova objetiva sobre a validade de conhecimentos indemonstráveis. Princípio materiais servem como ponto de partida para uma prova cujo objetivo é demonstrar a própria validade de princípios assim formulados. Tanto é assim, esta circularidade, que Kant teve a ideia, no \$37, de importar a validade universal para dentro do conteúdo semântico do juízo:

Portanto, não é o prazer, mas a validade universal deste prazer, que é percebida como ligada no ânimo ao simples ajuizamento de um objeto, e que é representada a priori em um juízo de gosto como regra universal para a faculdade do juízo e válida para qualquer um. É um juízo empírico o fato de que eu perceba e ajuíze um objeto com prazer. É, porém, um juízo a priori que eu o considere belo, isto é, que eu posso imputar aquele comprazimento a qualquer um como necessário. (CFJ, 135)

Ora, uma coisa é afirmar que "a é belo" implica dizer que "a é objeto de um comprazimento para o qual não há fundamento particular". Logo, não estou em contradição com as condições formais do juízo ao pretender universalidade para ele. Mas isso pode ser uma ilusão. Apenas se existir um sentido comum é que se pode presumir, com direito, que é possível a universalidade sem conceito em geral. Por isso, outra coisa bem diferente é afirmar que " $a$ é belo" equivale a: "não é possível dizer que $a$ é objeto de um comprazimento para o qual não há fundamento particular se não com pretensão de universalidade", como se o sujeito que julga um objeto belo fosse um filósofo. O que tem que ser provado foi transferido, falaciosamente, para o próprio conteúdo semântico do juízo.

Então, quando uma pessoa diz " $a$ é belo", não apenas quer dizer ' $a$ é belo’ e, além disso, requer que todos concordem, caso haja um sentido comum. Mas ela também diz " $a$ é belo e isso é um juízo que eu não posso emitir se não com pretensão universal". Só que ela emite com pretensão de universalidade precisamente que " $a$ é belo e eu não posso emiti-lo se não com pretensão 
universal", isso tudo ao dizer simplesmente que " $a$ é belo". Pois ela ajuíza, desde já, sobre o fundamento de que haja um sentido comum, que ainda precisa, contudo, ser provado. A primeira circularidade pode ser assim formulada: o sentido comum toma como não problemáticos certos tipos de juízos, e estes são usados numa suposta prova de que haja um sentido comum.

\subsection{O problema da "subsunção" - segunda circularidade}

Um dos principais problemas enfrentados pela teoria estética de Kant é, obviamente, que o fundamento do juízo é ele mesmo estético, e não conceitual. Isto quer dizer que a universalidade do juízo é antes sentida do que postulada, daí a implicação de que o sujeito que ajuíza um objeto como sendo belo imputa a universalidade, que ele sente, a qualquer um, mas não conhece os vínculos conceituais que o filósofo transcendental, então, deve dar a conhecer. Isto parece estar em conflito com a suspeita anteriormente levantada sobre as "confusões" entre os níveis de argumentação, isto é, de que a universalidade do gosto é transferida para o próprio conteúdo semântico do juízo, o que implica dizer que aquele que profere um juízo de gosto nem pensaria em usar o termo "belo" se não com pretensão de universalidade, como se conhecesse seus fundamentos filosóficos. Entretanto, o conjunto desses fundamentos, que é a sua ratio essendi, por assim dizer, é trazido à tona imediatamente no próprio sentimento, que é a ratio cognoscendi daquilo que toda filosofia transcendental do gosto tenta, então, tornar explícito.

O problema da subsunção reside no fato de que o sentimento é, afinal, tudo de que se dispõe para fundamento do juízo, uma vez que não é possível confundir o ponto de vista daquele que julga o objeto belo com o próprio ponto de vista transcendental. Como pode, entretanto, estar certo aquele que julga um objeto belo a respeito da correção de seu próprio juízo? Isto é, como ele sabe se não imiscuiu no seu juízo nenhum atrativo ou comoção? Do ponto de vista filosófico, Kant mostrou que esta ideia não é contraditória, revelando sua possibilidade lógica, mas sua possibilidade real só é possível a partir do pressuposto de um sentido comum. Neste caso, como aquele que julga um objeto belo pode avaliar se fez do seu sentimento particular um exemplo do sentido comum? Ora, se o fundamento é exclusivamente subjetivo, então tudo 
o que se tem é a indicação, a força de universalidade inerente ao próprio sentimento, mas não uma regra determinada que funcione como teste para saber se o princípio da faculdade de julgar, no seu uso sem conceitos, foi corretamente aplicado ou não. Sobre isto Kant claramente oscila.

Em nota ao $₫ 38$, ele afirma:

Para ter direito a reivindicar um assentimento universal em um juízo da faculdade de juízo estética, baseado simplesmente sobre fundamentos subjetivos, é suficiente que se conceda: 1) que em todos os homens as condições subjetivas desta faculdade são idênticas com respeito à relação das faculdades de conhecimento aí postas em atividade em vista de um conhecimento em geral; o que tem que ser verdadeiro, pois do contrário os homens não poderiam comunicar entre si suas representações e mesmo o conhecimento; 2) que o juízo tomou em consideração simplesmente esta relação (por conseguinte a condição formal da faculdade do juízo) e é puro, isto é, não está mesclado nem com conceitos do objeto nem com sensações enquanto razões determinantes. Se também a respeito deste último ponto foi cometido algum erro, então ele concerne somente à aplicação incorreta a um caso particular da autorização que uma lei nos dá; mas com isso a autorização em geral não é supressa (CFJ, 136 Nota $150)^{8}$.

Ora, Kant está dizendo, basicamente, que existem apenas duas condições para reivindicar assentimento universal em um juízo de gosto. Primeiramente, deve haver uma faculdade de sentir idêntica em todos os homens, que é uma condição subjetiva do conhecimento, assim como o sentimento de convicção que o acompanha e que é comunicado junto com o conhecido. Em segundo lugar, que o juízo de gosto seja verdadeiramente puro. Ora, ainda que a primeira condição tivesse sido demonstrada, o que não é o caso, ainda assim estaríamos reféns do fato de que não há nenhum indicativo conceitual claro de que um juízo concreto conseguiu aplicar este princípio corretamente, pelo contrário, a única evidência de que um tal princípio exista é a própria força de convicção inerente ao juízo, isto é, o caráter exemplar da necessidade ligada em um juízo de gosto. Se não, não seria uma validade exemplar. O princípio da faculdade de julgar é ele mesmo um princípio de aplicação, e fica difícil dizer como sua validade pode ser mantida mesmo que a

\footnotetext{
${ }^{8}$ Os negritos inexistem no original.
} 
aplicação tenha sido incorreta. Kant tinha deixado escapar este pensamento anteriormente:

O sentido comum, de cujo juízo indico aqui o meu juízo de gosto como um exemplo e por cujo motivo eu the confiro validade exemplar, é uma simples norma ideal, sob cuja pressuposição poder-se-ia, com direito, tomar um juízo - que com ela concorde e um comprazimento em um objeto, expresso no mesmo - regra para qualquer um; porque o princípio, na verdade admitido só subjetivamente, mas contudo subjetivo-universal (uma ideia necessária para qualquer um), poderia, no que concerne à unanimidade de julgantes diversos, identicamente a um princípio objetivo, exigir assentimento universal, contanto que apenas se estivesse seguro de ter feito a subsunção correta (CFJ, $85)$.

Aqui, fazendo justiça à ideia de uma validade exemplar, podemos dizer que a validade do sentido comum se apoia no caráter exemplar do meu juízo tanto quanto o meu juízo se apoia no caráter transcendental do sentido comum. Sendo subjetivo, mesmo que universal, o princípio pode ser mal aplicado. Neste caso, só valeria enquanto princípio universal, porém subjetivo, se a aplicação tiver sido feita corretamente. Mas disso não se tem nenhum critério se não o próprio sentimento, que é resultado da aplicação do princípio. A indecisão a respeito dessa questão ou, melhor dizendo, o fato de que Kant, por probidade filosófica, muitas vezes é levado a conduzir argumentos contra si mesmo, é evidente nesta "Observação" imediatamente posterior à nota citada:

Ora, conquanto este último ponto contenha dificuldades inevitáveis, que não são inerentes à faculdade do juízo lógica (porque nesta se subsume sob conceitos), na faculdade do juízo estética, porém, sob uma relação - que meramente pode ser sentida - da faculdade da imaginação e do entendimento reciprocamente concordantes entre si na forma representada do objeto, em cujo caso a subsunção facilmente pode enganar; mas com isso não se tira nada da legitimidade da pretensão da faculdade do juízo de contar com um assentimento universal, a qual somente termina no julgar a correção do princípio a partir de fundamentos subjetivos de um modo válido para qualquer um (CFJ, 137).

Salta à vista, nesta passagem, que a relação expressa em um juízo de gosto, inclusive a relação à universalidade, apenas pode ser sentida. Estranhamente, a legitimidade do princípio é mantida, embora a aplicação 
possa enganar e o sujeito acabar sentindo que aplicou corretamente o que não foi aplicado corretamente, mas não há como sabê-lo. Daí as dificuldades inevitáveis da questão. Contudo, julgando a correção do princípio somente a partir de fundamentos subjetivos, que é sua aplicação, poder-se-ia concluir que o princípio é legítimo. A segunda circularidade pode ser assim formulada: a prova da validade universal do direito à correta subsunção garante a validade universal de um sentimento, mas o sentimento é ele mesmo o modo de "consciência", o fundamento subjetivo, da validade universal do direito à correta subsunção.

\section{Por que a prova de que há um sentido comum sofre de circularidades lógicas?}

Ora, como é possível demonstrar que há um sentido? A resposta mais imediata é dizer que ele está contido na consciência empírica de uma experiência, isto é, que claramente identificamos uma experiência adquirida através dele, como um fato da cognição. Não há uma prova de que existe o olfato! Mas, ao contrário dos demais sentidos exteriores, o sentido comum não é óbvio assim. Portanto, a resposta menos óbvia de que há um sentido comum seria mostrar, como Kant tenta, que há uma necessidade de pressupor um tal sentido, sem o qual uma determinada propriedade do conhecimento seria perdida, neste caso, sua comunicabilidade. Mas nós vimos que este argumento não é satisfatório. A comunicabilidade é de fato estética, isto é, sentida. Neste caso, não é possível justificar o pressuposto de um sentido comum nem com o auxílio à experiência nem com um argumento lógico ou transcendental. Ele seria, assim, uma espécie de factum. Com surpreendente semelhança, esta "solução", sem maiores explicações, é dada igualmente por Aristóteles no Livro III do De Anima e pelo próprio Kant na Crítica da Raz̃ão Pura, antes da descoberta de um suposto princípio da faculdade de julgar. Uma alternativa, que se distancia da perspectiva kantiana da terceira Crítica, seria reinterpretar positivamente esta circularidade, orientando-se pela ideia de um factum da cognição, mas com uma explicação adicional, que é a solução dada por Tomás de Aquino na Questão 78 da Suma Teológica e desenvolvida ao longo de sua obra. Ao examinarmos estas possibilidades estaremos ao mesmo tempo 
reconstruindo uma história um pouco mais longa do conceito de um sentido comum?

\subsection{Porque é um factum e não é possivel prová-lo}

A lógica transcendental de Kant não é apenas uma lógica formal da articulação de proposições, mas a lógica da aplicação correta de regras que podem ser julgadas legítimas dentro de certas condições sensíveis. É uma lógica do emprego de categorias e princípios dentro de seus domínios de aplicação, a saber, a experiência. Surge, neste caso, a pergunta de quais regras, categorias ou princípios deveriam ser seguidos para assegurar que uma determinada regra, categoria ou princípio seja aplicada corretamente. Por exemplo, que regra devo utilizar para saber a qual ente empírico devo aplicar o conceito empírico de cadeira? Um estudante de medicina aprendeu todas as propriedades conhecidas de um câncer de fígado, e possui as notas características da regra fornecida por este conceito empírico. Que regra ele deve seguir para identificar, na experiência, um caso que cai sob este conceito? Em suma, qual é, em geral, a regra da faculdade de julgar? Até a Crítica da Faculdade do Juíro, essa regra não existia, para Kant:

Se essa lógica quisesse mostrar, de uma maneira geral, como se deve subsumir nestas regras, quer dizer, discernir se algo se encontra ou não sob a sua alçada, não poderia fazê-lo sem recorrer, por sua vez, a uma regra. Esta, sendo uma regra, por isso mesmo exige uma nova instrução por parte da faculdade de julgar; assim se manifesta que o entendimento é, sem dúvida, susceptível de ser instruído e apetrechado por regras, mas que a faculdade de julgar é um talento especial, que não pode de maneira nenhuma ser ensinado, apenas exercido. Eis porque ela é o cunho específico do chamado bom senso, cuja falta nenhuma escola pode suprir (CRP A 133/B 172).

Ora, muito semelhante argumento é levantado por Aristóteles para a

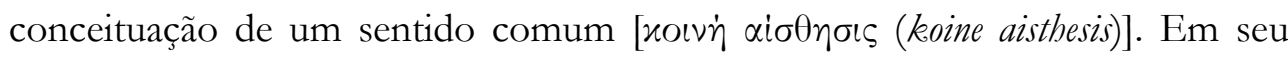
contexto, o Estagirita pretende classificar todas as sensações experimentadas pelos animais sem imperfeições físicas ou mutilações, e faz considerações sobre os quatro elementos e os cinco sentidos exteriores, dando ênfase ao ar e à água, meios pelos quais os sentidos atuam, e supõe que se não há nenhum

9 Mais longa do que a esboçada em "Breve história do conceito de sensus communis". In: GRUPILLO, 2016, pp.201-213, que trata basicamente da relação do conceito com a tradição humanista latina e com o iluminismo escocês. 
outro elemento, além de fogo e terra, também ele não deve ter deixado escapar nenhum outro sentido desconhecido. A cada sentido particular acompanham

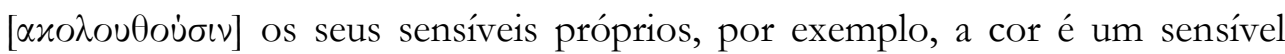
próprio da visão. No entanto, existem sensíveis comuns, como o movimento, o repouso, a figura, a grandeza, etc., que acompanham mais de um sentido exterior. É neste contexto que "sentido próprio" ocorre em oposição aos

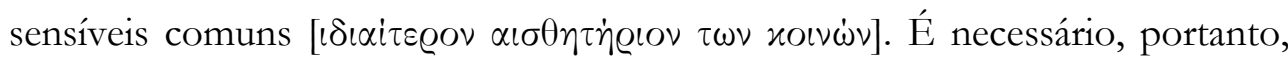
que um sentido comum percepcione o "trabalho" dos sentidos exteriores, para que a bílis, que é amarga e amarela, sensíveis próprios de sentidos particulares distintos, não seja confundida com um quindim, um outro objeto amarelo, mas que, no entanto, é doce. É uma questão, portanto, semelhante à do juízo para Kant, sem a exigência de uma aplicação de conceitos, pois se trata de uma teoria do psiquismo animal ${ }^{10}$. Ocorre que, se um outro sentido percepciona a vista, que outro sentido percepciona este sentido que percepciona a vista, para que não se confunda o seu sensível com o de outro sentido próprio? Ora, este sentido não pode, ele mesmo, ser um sentido próprio, pois cabe a ele reunir o que é próprio de cada sentido particular numa única percepção. Daí a distinção entre sentido particular e sentido comum, que não é acompanhado por nenhum sensível próprio. Do contrário, seriam necessários infinitos sensíveis que percepcionassem os seguintes.

\begin{abstract}
Uma vez que percepcionamos $[\alpha \iota \sigma \theta \alpha \nu \dot{\mu} \mu \varepsilon \theta \alpha]$ que vemos e que ouvimos, é necessário que percepcionemos que vemos ou com a vista, ou com algum outro sentido. O mesmo sentido, assim, percepcionaria a vista e o seu objeto, isto é, a cor, de tal forma que ou haverá dois sentidos que percepcionam o mesmo, ou um sentido se percepcionará a si mesmo. Mais, se o sentido que percepciona a vista for diferente, ou <formarão uma série $>$ até ao infinito, ou haverá algum sentido <nessa série> que se percepcione a si mesmo, de modo que é preferível assumir isso em relação ao primeiro da série (ARISTÓTELES, 2010, 425b).
\end{abstract}

O sentido comum é, portanto, o primeiro da série dos sentidos, pois percepciona a si mesmo. Isso significa que não é percepcionado, ou corrigido, por nenhum outro sentido. Somente, em seres mais inteligentes, por uma faculdade intelectual, isto é, em um animal racional. É, portanto, um fato do

10 Talvez por isso a relação com o problema faculdade de juízo estética, que é, para todos os efeitos, "sem conceito". Tentaremos esclarecer isto adiante. 
psiquismo, que Aristóteles deriva da reflexão sobre o comportamento animal, que não tem lugar numa teoria idealista do conhecimento exclusivamente conceitual. O que permanece em Aristóteles é a perspicácia de observação reflexiva, como, por exemplo, o fato de que discriminamos a luz e a escuridão mesmo de olhos fechados. E mais ainda, existem, em continuação do sentido comum, a imaginação e a memória, pois "ainda que os sensíveis se tenham afastado, as sensações e as imaginações permanecem nos órgãos sensoriais" (ARISTÓTELES, 2010, 425b). Aqui, de certo modo, já se anuncia também a importância da contribuição de São Tomás para a história do conceito de sensus communis.

\subsection{O sentido comum é ele mesmo uma questão de sentido comum}

O sistema teórico no qual se insere o conceito de sensus communis na filosofia tomista é tão amplo que devemos ter o cuidado aqui de não nos perdermos em sutilezas demasiadas. Nenhumas delas, contudo, inútil, como às vezes se costuma dizer pejorativamente do pensamento escolástico. Pelo contrário, é a sofisticação de observação dos fenômenos naturais, incluindo os psíquicos, e a exigência de integrá-los logicamente num sistema também complexo de teoria do conhecimento e da inteligência, até, por fim, numa metafísica do ente, com a admissão, se necessária, de ideias teológicas, que a coloca em condições de responder a problemas impossíveis para algumas teorias modernas do conhecimento, como a de Kant. As restrições, portanto, serão apenas de natureza hermenêutica, a fim de não perder o fio condutor da argumentação. Mas é preciso ter em mente que a resposta tomista ao problema kantiano depende de seu completo sistema de filosofia, inabarcável.

Em contrapartida, o lugar desse conceito no todo do próprio sistema tomista não é de ser subestimado. O biógrafo e apologista G.K. Chesterton, enfatizando a centralidade desse conceito, comentou que, mesmo com toda sua abstração e aparente frieza, "a filosofia tomista está mais próxima da mente do homem que anda nas ruas do que a maioria das outras filosofias" (CHESTERTON, 2004, p.66), e sabemos que um renomado medievalista assegurou que a perspicácia de Chesterton teria "lançado na vergonha" a especialidade de muitos que "levaram vinte ou trinta anos estudando St. 
Tomás" (GILSON apud CLEMENS, CYRIL, 1972, p. 150). Sobre as relações com a própria filosofia, J. Maritain afirmou:

[A filosofia] deriva do senso comum, se nele for considerada a inteligência dos princípios imediatamente evidentes. Ela é superior ao senso comum tal como o estado perfeito ou 'científico' de um conhecimento verdadeiro é superior ao estado imperfeito ou 'vulgar' desse mesmo conhecimento. Todavia, a filosofia pode ser por acidente julgada pelo senso comum (MARITAIN apud GARDEIL, 2013a, p. 54) ${ }^{11}$.

O comentário certeiro de Maritain, sobre a superioridade da filosofia mas sua eventual correção pelo senso comum, realiza sutilmente um ajuste do que pode ser considerado, como teremos oportunidade de ver, um "dogma do peripatetismo", um “ídolo aristotélico", nas palavras de Pierre Rousselot (1999, p. 117). Tomás, obviamente, herdou a ideia aristotélica de que o intelecto descobre o que é comum a um grupo de indivíduos, "com desprezo de todas as notas individuantes", mas mesmo aí é preciso examinar "mais atentamente o que isto quer dizer e como acontece." (CARVALHO in: AQUINO, 2013, p. 35). Consequentemente, herdou também a ideia de que conhecimento é sempre conhecimento por causa, daí a prioridade da filosofia sobre o conhecimento julgado imperfeito ou vulgar. Mas sua teoria permite integrar no "fim da natureza" não somente as espécies, mas também os acidentes individuais, estando mais apta, assim, a refletir sobre a experiência do belo e da $\operatorname{arte}^{12}$.

O principal texto em que aparece uma discussão sobre o sensus communis na obra de Tomás é a Questão 78 da Suma Teológica, no qual, segundo Gardeil, "são Tomás se dedicou a dar uma justificação a priori da existência desses sentidos [internos]", entre os quais o sentido comum (GARDEIL, 2013b, p. 69). A questão trata da psicologia do animal sem imperfeições físicas, que, tendo de se deslocar para atender suas necessidades, deve ser capaz de "representar" para si os objetos sensíveis, mesmo quando não estão presentes. $\mathrm{O}$ modo de dizer da teoria moderna do conhecimento às vezes incomoda. Para que o animal possa discernir o que convém ou não convém a si, deve possuir

11 Gardeil também acrescenta - o que para nós mostra continuidade na problemática: "Exprimindo-se assim, J. Maritain entende situar a filosofia tomista, na qual ele pensa, entre as afirmações simplistas da escola escocesa, e algumas pretensões da crítica moderna”.

12 Sobre isso, apoiamo-nos especialmente em Rousselot. 
um certo sentido para o útil e o nocivo, o que seguramente não pode ser atribuído aos sentidos exteriores nem ao conhecimento conceitual.

Não é inteiramente claro o que Gardeil designa por "justificação $a$ prior ${ }^{\prime 13}$. Certamente não se trata de apoiar a existência de um sentido comum naquilo que unicamente é "válido objetivamente", isto é, no conhecimento e suas condições, o que poderíamos chamar de "prova idealista", mas sim em uma "riqueza de observações e uma verdadeira fineza de discernimento psicológico" (GARDEIL, 2013b, p. 69), isto é, numa observação e discernimento do agir (movimento) e suas condições, o que poderíamos chama de "prova realista". A abordagem das "condições" que possibilitam o que acuradamente se observa - diferente das condições que possibilitam o caráter objetivo da autoconsciência empírica - é verificada nas primeiras palavras de Tomás: “Como a natureza não falta no que é necessário, é preciso haver tantas ações da alma sensitiva quantas se requerem para a vida de um animal perfeito" (AQUINO, 2002, p. 431) ${ }^{14}$. Além disso, o sentido comum é requerido como para conservação, na memória, dos sensíveis. Tendo em vista que o animal age, isto é, se move em busca do alimento que não está diante de seus sentidos externos, “deve haver uma potência para receber as espécies dos sensíveis, e outra para conservá-las" (AQUINO, 1ª q.78 a.4). O agir que se segue ao ser é, também aqui, parte de uma filosofia geral do movimento, que se observa com características específicas, tanto na ordem mineral quanto na vida animal. No animal, este movimento obedece à finalidade específica da distinção entre o conveniente e o nocivo:

Se um animal só se põe em movimento por objetos agradáveis ou repugnantes para os sentidos, não haveria necessidade de afirmar no animal senão a apreensão das formas que o

\footnotetext{
13 Talvez o próprio Gardeil se possa contar, seguindo a tipologia dele mesmo, no "tomismo antikantiano" de Rousselot, diferente do tomismo histórico-teológico de Gilson ou da categoria particular de Maritain, por exemplo. Cf. GARDEIL, 2013a, p.12. O mais importante é que, para nossos propósitos, procuramos trabalhar com os intérpretes de Tomás mais dedicados aos problemas da filosofia transcendental.

14 Daqui em diante, usaremos a indicação mais comum: $1^{\mathrm{a}}$ q.78 a.4, querendo dizer Parte I, Questão 78, Artigo 4, notação que pode, eventualmente, não ser familiar ao leitor que chegou até aqui por interesse num problema da estética, e da estética de Kant. Pela mesma razão, abusamos de referências a trabalhos introdutórios sobre Tomás, conscientes de que o alcance exegético deles é, muitas vezes, limitado, em especial o de Gardeil. O presente trabalho tem muito mais um caráter programático, de chamar atenção para uma ideia a ser desenvolvida, do que propriamente o de uma versão acabada desta mesma ideia. Os estetas poderão estranhá-lo, e especialistas em Tomás poderão entrever sutilezas esquecidas. O mais importante é que elas não comprometam o argumento central.
} 
sentido percebe e com as quais sente prazer (delectatur) ou repugnância. Mas é necessário que o animal procure umas coisas ou fuja de outras, não só porque convêm ou não ao sentido, mas também por outras conveniências e utilidades ou nocividades. Por exemplo: a ovelha que vê o lobo chegar foge, não porque a sua cor ou sua forma não são belas (indecentiam), mas porque é seu inimigo natural" (AQUINO, 1ª q.78 a.4).

E aqui parece impossível qualquer relação direta com o belo no sentido estético, de prazer artístico, sobretudo tendo em vista as proposições de Tomás sobre o tema mais comumente citadas, por vezes apenas a título histórico. Em parte, porque ele entende o belo como espécie do "conveniente" ou, dito de maneira mais clara: "Belo é o mesmo que o bom; ele não se difere a não ser racionalmente" (AQUINO, 2 $2^{\mathrm{a}}$ q.27 a.1). Em parte, porque as artes são compreendidas entre as últimas na ordem das ciências (lógica, especulativa, prática e poética), também chamadas ciências da produção ou "artes mecânicas". ${ }^{15}$ O conveniente e o nocivo estão, sem dúvida, inscritos no necessário que a natureza não falta para tornar possível a vida do animal perfeito, e por isso constituem parte de uma filosofia do movimento, no sentido de ir em direção ao que dá prazer e fugir ao que é repugnante, como a ovelha foge do lobo, não por razões meramente "estéticas", por assim dizer, mas porque é seu inimigo natural, na ordem do fim da natureza. Mas há ainda outras razões para considerar a passagem como não tão simplória. Depois de algumas considerações conceituais, incluindo um excurso histórico-filológico, poderemos colocar a questão do porquê de a busca do conveniente e do nocivo, no animal racional, comportar mais amplitude.

O termo vertido por "belo", nesta passagem, não é o habitual pulchrum, mas indecentiam, que pode ser definido como "o que não convém”, do verbo inděcěo, ère, "não convir" ou "to misbecome"16. Em rara aparição no período pósAugusto, encontramos a seguinte passagem de Plínio, o Jovem:

Ignoro se passei algum período de tempo mais agradável (iucundius) do que o que vivi faz pouco com Espurina, certamente a tal ponto que não quero emular a mais ninguém em minha velhice, se é que me é permitido envelhecer; pois não há nada mais distinto que seu modo de vida. Quanto a mim, assim como o movimento regular

${ }^{15}$ Metafísica, VI, I. 1, n. 1152. Citado em GARDEIL, 2013a, p. 223.

${ }_{16}$ Cf. Lewis \& Short. A Latin-English Lexicon. Disponível em: <http://www.perseus.tufts.edu/hopper/>. Acesso em: out. 2016. 
dos astros, me agrada também a vida metódica das pessoas, sobretudo a dos anciãos: pois nos jovens não são indecorosas (indecent) apenas certas atitudes desordenadas e por assim dizer perturbadas; tudo o que é aprazível (placida) e organizado convém (conveniunt) aos anciãos, para quem a laboriosidade é extemporânea e a ambição, indigna (Epístolas III. 1,1-2) ${ }^{17}$.

Isso significa que indecent não é apenas o impróprio no sentido de inadequado, que não convém (como meio para um fim) pois, para isso, há o vocábulo convenient. Indecent significa também o aprazível, mas no sentido de plácido, suave e calmo, em oposição ao que é desordenado e perturbador. Aliás, é particularmente interessante se perguntar como a estética moderna, sem dúvida sob influência da categoria do sublime, tornou o prazer no belo - para o próprio Kant, um "cum alio placere" ou "Woblgefallen", isto é, um comprazimento - numa categoria que designa sobretudo a vivificação ou excitação das faculdades cognitivas. Mas o fato é que, na passagem de Tomás, vemos claramente a distinção entre um tipo de prazer/repugnância que convém ou não ao sentido e ainda "outras conveniências ou nocividades", entre as quais a nocividade do inimigo natural. Mas isso não exclui o prazer no belo como um tipo de conveniência ao sentido sem finalidade definida para a espécie, o que condiz com a clássica definição de Tomás de que "pulchra enim dicuntur quae visa placenta" (“diz-se belo aquilo que agrada ao olhar”) (AQUINO, $1^{\mathrm{a}}$. q. 5 a.4 $)^{18}$.

No entanto, é particularmente inquietante a grave denúncia que Umberto Eco fez da aceitação, nos estudos gerais de Tomás, das palavras de Maritain: "pulchrum est id quod visum placet" ("belo é o que agrada à vista"). Segundo ele, Maritain teria inventado citações tomistas "inexistentes" para defender a ideia de um senso intelectivo [sens intelligencie] a fim de identificar o prazer no belo com a "alegria estética", o que, para Eco, "é uma espécie de ideia tipicamente moderna, que um filósofo medieval, mais do que rejeitar,

\footnotetext{
${ }^{17}$ Disponível em: <http://members.aon.at/latein/Plinius14.htm>. Acesso em: out. 2016.

$18 \mathrm{O}$ belo (pulchrum) é, no espírito de Agostinho, um tema metafísico do "ver", de uma relação ao caráter transcendental de Deus (bonum, unum, ens, pulchrum) e de fato não aparece na passagem da Suma sobre os sentidos internos, que tem em vista, muito mais, uma teoria do conhecimento sensível. O desafio deste trabalho é apontar uma conexão possível entre os dois âmbitos. Pode ser que, por isso, o leitor tenha a impressão de que se passa de um aspecto ao outro muito rapidamente. As limitações deste artigo, contudo, e seu caráter ao mesmo tempo extremamente técnico e de longo alcance filosófico, nos impedem de dar um tratamento mais demorado a cada questão. Esperamos, em momento oportuno, resolver algumas lacunas.
} 
simplesmente não teria entendido" (ECO, 2014, p. 314). Mas talvez o pathos historicista de Eco seja demasiado dogmático aqui. Mesmo concedida a precaução na compreensão histórica, isso não significa, de modo algum, que não há lugar para a finalidade não específica do belo, que possa diferir de indivíduo para indivíduo - ao contrário do conveniente específico natural -, na psicologia e na metafísica tomista. A distinção, mesmo que não desenvolvida, está explícita no texto de Tomás:

Igualmente o passarinho recolhe a palha, não pelo prazer sensível, mas porque é útil para construir o ninho. Portanto é necessário que o animal perceba tais intenções que o sentido externo não percebe. Deve haver, em consequência, um princípio próprio dessa percepção, pois a percepção das formas sensíveis é por uma modificação do objeto sensível, não porém a percepção das intenções referidas (AQUINO, $1^{\text {a }}$ q.78 a.4 $)^{19}$.

Aliás, na própria passagem que teria sido adulterada por Maritain, podemos ver novamente uma clara distinção, e mesmo razoavelmente desenvolvida numa determinada direção que, entretanto, pode ter de sofrer ajustes, se queremos fazer justiça tanto à ideia que procuramos quanto ao pensamento geral de Tomás. Pois ali ele escreve:

Deve-se dizer que o belo e o bem, no sujeito, são idênticos, pois estão fundados sobre o mesmo, a saber, sobre a forma. Por isso, o bem é louvado como belo. Mas diferem pela razão. O bem propriamente se refere ao apetite, pois o bem é aquilo para o qual tudo tende, e assim tem a razão de fim; pois o apetite é uma espécie de movimento rumo à coisa. Quanto ao belo, ele se refere à faculdade de conhecimento, pois diz-se belo aquilo que agrada ao olhar. Eis por que o belo consiste numa justa proporção, pois os sentidos se deleitam em coisas bem proporcionadas, como nas semelhantes a si, uma vez que o sentido, como toda faculdade cognitiva, é uma certa razão. E como o conhecimento se realiza por assimilação, e a semelhança se refere à forma, o belo, propriamente, pertence à razão de causa formal (AQUINO, 1 ${ }^{\mathrm{a}}$. q.5 a.4. ad.1).

Vê-se, na passagem, a identidade de bem e belo sob o aspecto formal. No entanto, o belo é, apenas quanto à razão, abstraído da relação de causa final, do fim ao qual tudo tende, e julga-se sua racionalidade não em relação a este fim, mas à forma interna (proporção, medida, etc.). Limita-se, assim, o alcance da relação do belo com a finalidade última, quando considerado apenas

${ }^{19}$ Cf. também AQUINO, 2012 (Questão XIII). 
sob o aspecto da relação com a faculdade cognitiva, o que não é incorreto do ponto de vista da filosofia de Tomás. Mas pode ser que uma consideração do belo sob o aspecto da relação ao fim último não esteja em desacordo com esta mesma filosofia, pelo contrário. Deste modo, guarda-se a diferença no que diz respeito à relação com a faculdade cognitiva no homem, que é imperfeita, mas não com a intelecção divina, que é perfeita, e que não deixa de assimilar nenhuma razão e nenhuma potência. Isto é, diferentemente do intelecto humano débil, o intelecto por si não despreza nenhuma nota individuante. Isto é o que importa provar. É neste sentido, também, que a reflexão sobre o sensus communis tomista começa aí, mas não se limita ao nível da reflexão sobre a cognição humana.

Agora, bem. Em Kant, não há um conceito que explique porque a representação "inimigo", para a ovelha, segue-se à representação "lobo", porque a ovelha, obviamente, não conhece por conceitos. Assim como não há um conceito que explique porque a representação "prazer", para nós, segue-se à representação "belo" (exemplar, esta coisa bela), porque o belo é objeto de um comprazimento universal sem conceito. Mas, então, como Kant sabe, sem conceito, que é universal? Aqui, como sabemos, as provas (idealistas) fracassam. Ao contrário, Tomás se refere à necessidade de pressupor a existência de um sentido comum porque entende que há uma percepção sintética de sensíveis comuns, e não meramente dos dados sensíveis exteriores, da qual depende, por sua vez, a percepção de intenções na natureza. Esta se chama vis aestimativa, quando percebe essas intenções nos animais superiores, por exemplo, quando a ovelha foge do lobo; e se chama vis cogitativa, quando referida à faculdade de conhecimento humana. É aí que discerne primeiramente que "a natureza não falta no que é necessário", mas só consegue atribuir, por causa final, o necessário da espécie, não o necessário do indivíduo (este lobo ou esta ovelha, por exemplo). A duplicação do sentido comum se dá porque a ovelha percebe o lobo, e o homem - neste caso o filósofo - percebe que a ovelha percebe o lobo e isso tem consequências para ela. Aquilo que o homem sente por sentido comum é completado por um conhecimento superior, filosófico, sobre o fim da natureza, porém, que deixou perder algo percebido pelo sentido comum, completado pela vis cogitativa, algo que não 
alcança o nível do conceito humano, que é a importância desta ovelha no fim da natureza. E isto é fundamental na reflexão sobre o belo e a arte.

Se temos a necessidade de explicar isso unicamente com referência ao conhecimento objetivo e suas condições, como quer Kant, isto é, com referência à única coisa que pode ser tomada como ponto de apoio em alguma prova definitiva, recaímos nos problemas já mencionados. Mas Tomás não tem nenhuma necessidade de se apoiar unicamente no que considera um conhecimento objetivo, mas sim num tipo de conhecimento ainda anterior, que é sua primeira premissa, a saber: "Como a natureza não falta no que lhe é necessário, é preciso haver tantas ações da alma sensitiva quantas se requerem para a vida de um animal perfeito". E como Tomás sabe que a natureza não falta no que lhe é necessário? Em parte, por uma premissa filosófica fundamental, que é o fim último. Em parte, por sentido comum, referido, repito, à vis cogitativa, que nele mesmo intui essas intenções, revelando um interessante aspecto metateórico no problema. ${ }^{20}$

Isto porque, como dissemos, Tomás faz uma distinção sobre como esta natureza atua nos brutos e no animal racional. Este sentido, no homem, está muito próximo da faculdade cognitiva, e está na base do que ele chama rąão particular ou "razão cogitativa", porque opera por comparação, ao contrário da faculdade meramente estimativa dos outros animais.

Por isso, a potência que se denomina nos animais de estimativa natural é chamada no homem de cogitativa, porque descobre essas intenções por uma espécie de comparação. Chama-se, ainda, razão particular [ratio particularis]. (...) Por exemplo, discernindo o branco do preto ou do verde. Mas discernir o branco do doce, nem a vista nem o paladar podem fazê-lo: pois para discernir uma coisa de outra, é preciso conhecê-las a ambas. É, portanto, ao senso comum que pertence fazer o discernimento, pois só a ele são referidas, como a um termo comum, todas as apreensões dos sentidos, e é por ele ainda que são percebidas as intenções dos sentidos (AQUINO, 1 ${ }^{\mathrm{a}}$. q.78 a.4 - tradução modificada).

\footnotetext{
${ }^{20}$ Daí a exemplaridade da interpretação de Chesterton que, mesmo sem se aprofundar em detalhes da obra tomista, captou seu espírito ao afirmar que "o fato de o tomismo ser a filosofia do senso comum é, ela mesma, uma questão de senso comum" (CHESTERTON, 2004, p.65). Para um estudo mais aprofundado do tema e da variedade dos sentidos internos em Tomás, cf. TELLKAMP, 2012, pp 611-40.
} 
Por exemplo, o homem compara que a ovelha foge do lobo, mas o gato foge da água. $\mathrm{O}$ homem percebe que de uma certa altura não pode pular sem se machucar, mas de uma altura um pouco menor pode pular sem se machucar, depende do caso concreto. Não há uma altura, obviamente relativamente alta, determinada e que, dadas certas condições, o homem possa dizer que em geral pode pular sem risco. Talvez um gato pule de uma altura maior. O problema do sentido comum, no homem, é que ele é referido à faculdade de conhecimento, o que torna muito mais abrangente sua relação com a intelecção do ente singular, e exige não só todo aparato da psicologia e da metafísica tomista, como também um determinado aspecto da fé cristã, para a superação do dogma aristotélico de que apenas a espécie cumpre os fins da natureza e não o ente singular, isto é, o indivíduo. "O homem é mais potencial não porque tenha menos ser e ato que os brutos, mas porque, possuindo a inteligência, pode servir-se dela para dirigir e modificar seu organismo sensível, e adaptá-lo a muitos fins" (ROUSSELOT, 1999, p.123). O sentido comum, no homem, é mais flexível e mais potencial. Nem por isso a intelecção do concreto é menos real, pelo contrário, é mais real que a do bruto e, no entanto, mais plena de outras possibilidades para serem atuadas. Por isso, o belo pode ser inscrito na ordem da razão final, não apenas como razão formal, isto é, coisa proporcionada, mas também como ente individual, que enriquece em diferenças o gênero de que é semelhante ${ }^{21}$.

Para Rousselot, que viu o problema de modo exemplar, a teoria do indivíduo de Tomás é sua “obra-prima”. Mas viu também que não era inviável fazer este ajuste na posição tomista sobre o belo e a arte, por força mesma desta obra-prima. Como ser singular, o objeto belo pertence a um concurso complexo de causas, que só se deixa finalizar em Deus. É a doutrina cristã da Providência que livra o individual de ser unido à razão unicamente como acaso. "Sem dúvida, neste ponto a fé cristã o impede de seguir Aristóteles até o fim" (ROUSSELOT, 1999, p. 117).

Portanto, na medida em que o ser singular é, pela atuação simultânea, coincidente, de muitos elementos; na medida em que o fato real se compõe de muitas circunstâncias simplesmente coexistentes, o ser singular e o fato real

21 A universalidade do belo, portanto, pode ser dita, aqui, universalidade potencial, atualizada somente no fim último. Isso admitiria, como hipótese, ampla diversidade no gosto humano. 
escapam à dedução. Sei por que alguém cava seu campo, e sei por que encontra ali um tesouro, mas ignoro por que cavando seu campo encontra um tesouro. (...) Para ele, o sistema das causalidades conhecíveis ao homem não é um: são muitos, que se cruzam e se implicam um no outro. (...) A razão, portanto, mostra a Sto. Tomás que o detalhe do mundo escapa a seus silogismos. A observação the ensina também que escapa a suas concepções, que são do geral. E dissemos que ele reconhece nessa desproporção entre ideia e ser uma imperfeição da inteligência em forma humana. (...) Significa isso que o universo, concebido como conjunto, permanece ininteligível, ou mesmo que uma só das simultaneidades realizadas [por exemplo, que isto seja belo, a.g.] seja incompreensível ou sem razão? De modo nenhum. Em Deus tudo se contém, a ordem das realizações como a das essências; para ele não há acaso" (ROUSSELOT, 1999, p. 111-2).

A filosofia da natureza do Estagirita, assim como a de Tomás, compreende o ser singular, tanto quanto o fato concreto, como produto simultâneo de um complexo de causas (material, formal, eficiente e final) e consegue, assim, explicar tanto a regularidade de fenômenos quanto aqueles acontecimentos que parecem especiais, ou que, evidenciando um concurso de causas como única possibilidade explicativa, evidenciam também, em primeiro lugar, a imperfeição da inteligência humana, sobretudo na intelecção do singular. Ora, o que nos impede de compreender uma obra de arte ou a beleza de um objeto como o efeito de um tal concurso complexo de causas, que Aristóteles teria colocado no registro do acaso, mas a que a doutrina da Providência pode dar uma outra direção? A beleza natural ou de uma obra de arte é inexplicável no sentido de Kant, isto é, sem conceito, porque ela chega a ser tanto segundo a razão formal, que aponta aqueles aspectos tais como proporção e simetria, típicos de uma estética objetiva, mas também segundo a razão material, a eficiente (onde residiria o âmbito próprio do conceito kantiano) como, por fim, a razão final, que pode ser tanto a operativa quanto a intencional, isto é, a forma final que se pretende dar ao objeto e a intenção que se quer com ele ${ }^{22}$. Com isto certamente teríamos uma teoria objetiva da beleza, mas somente para um intelecto divino, não para o humano. Assim mesmo é, segundo Rousselot, o universo.

22 A distinção é formulada por Tomás como se segue: "Com efeito, existe algum fim na intenção que está além do fim da operação, como é claro em uma casa, pois, sua forma é o fim que termina a operação de construção; porém, a intenção deste não termina aí, mas se dirige a um fim ulterior, que é a habitação; de tal modo que se diz que o fim da operação é a forma da casa, enquanto a intenção é a habitação" (AQUINO, 2013, p.321-2 [Questão 3, Artigo 16]). 
Para ele, o cristianismo tinha, com sua doutrina da Providência, que se estende aos últimos insetos, sua estima infinita pela menor das almas individuais, uma moral incorporada em exemplos vivos, o mistério da Encarnação, um Deus pessoal, etc., tudo para "facilitar à filosofia uma apreciação mais justa do conhecimento concreto". (...) "Princípios que", nas suas palavras, "não devem desagradar a pensadores modernos que mais insistem sobre o vago e a pobreza da ideia geral e colocam a perfeição de nosso conhecimento em uma apreensão mais rica do indivíduo." Mas, teria sido "uma obra bem delicada para esse intelectualismo de uma civilização jovem, que quase não filosofou sobre a arte, e que não sabia transformar sua vida em gozo de estetas, fazer unir-se perfeitamente a razão ao individual" (ROUSSELOT, 1999, p. 109-10).

Não se trata aqui, apenas, da mera imposição de um dogma teológico, mas sim que, segundo os princípios do próprio Tomás, devido a sua origem comum, filosofia e teologia não podem se contradizer em relação ao mesmo objeto, como se houvesse duas verdades ${ }^{23}$. Neste ponto, em que a filosofia toca um aspecto da verdade revelada, a teologia "propõe à filosofia problemas ou soluções que esta não teria considerado" (GARDEIL, 2013a, p.58). A interessante demonstração de Rousselot está em comparar, mutatis mutandis, a singularidade do universo criado, com sua diversidade, e a singularidade do ente belo, cujo fundamento aparecerá em seguida:

"Se Deus fizesse outros mundos", diz ele [Tomás], "ou os faria semelhantes a este, ou dessemelhantes. Se os fizesse de todo semelhantes, seriam em vão (essent frustra), o que não convém à sua sabedoria"24 Eis uma primeira razão para fazer pôr, ou supor, a ausência da pura multiplicação material nesse espelho de Deus que é a criação. Se dois mundos não poderiam ser semelhantes, por que dois tigres, ou duas borboletas, ou duas amebas? (ROUSSELOT, 1999, p.122-3).

Nas Questões Disputadas sobre o Poder de Deus, Tomás esclarece o erro daqueles para quem a diversidade das coisas, ao contrário das naturezas ou essências, era imputada à causa material, como, por exemplo, os antigos

23 Trata-se da clássica crítica de Tomás ao maniqueísmo, que terá também um papel na argumentação a seguir, a propósito da integração da diversidade na finalidade última do mundo material.

${ }^{24}$ In 1 Cael 1.19, fim. Citado em ROUSSELOT, 1999, p.122 
filósofos naturais. Aponta também problemas na posição de Platão e dos maniqueístas, particularmente interessantes porque estes acreditavam que de Deus procedia apenas criaturas espirituais e incorruptíveis, e que as corporais e corruptíveis procediam de outro princípio. Aponta problema também na complexa teoria de Avicena, que teria estabelecido uma hierarquia desnecessária entre causas eficientes: na medida em que a inteligência primeira produz o primeiro ente, produz também a primeira inteligência inferior (que é potência em relação à primeira), e assim sucessivamente. O mais importante é como Tomás conclui sua posição contra Avicena, implicitamente referindo-se à doutrina da Providência para explicar a diversidade material deste ente singular que é o mundo:

Segue-se também desta posição, assim como das primeiras, que a beleza da ordem do universo seria casual, pois a diversidade das coisas não se atribui à intenção do fim, mas à determinação das potências ativas em relação aos seus efeitos (AQUINO, 2013, p.324 [Questão 3, Artigo 16]) ${ }^{25}$.

Aqui, Tomás claramente refere-se à beleza [decor] da ordem natural como inscrita no modo como a diversidade das coisas se liga à razão final, e não meramente à razão formal. A discrepância só pode ser explicada pela diferença entre a inteligência potencial e imperfeita do homem e a inteligência atualíssima e perfeita de Deus.

Mas a semelhança da forma do intelecto divino, visto que ele atinge até as mínimas coisas, como também a sua causalidade as atinge, manifesta-se até na singularidade de sua forma sensível e material. Logo, o intelecto divino pode conhecer os singulares, mas não o pode o intelecto humano (AQUINO, 1990, p. 117 [Capítulo 65.8]).

Isso nos dá a ocasião de concluir.

\section{Conclusão}

A inteligência humana não é capaz de inteligir o singular nem as intenções da natureza, próprias da rą̧ão cogitativa que se segue ao sensus communis, sem referi-las à faculdade dos conceitos e à abstração própria do modo humano de conhecer que, no entanto, é real segundo seu modo. Mas, no

${ }^{25}$ No original: "Sequitur etiam ad hanc positionem, sicut et ad primas, quod decor ordinis universi sit casualis, ex quo rerum diversitatem non adscribit intentioni finis, sed terminationi potentiarum activarum ad suos effectus". 
ser humano, este sentido comum tem função dupla. Do contrário, não poderíamos admitir que temos um tipo de intelecção para o qual não temos uma explicação conceitual. Ou, dito de outro modo, Kant não poderia dizer que há algo sobre o qual o conhecimento se apoia sem conceitos. Só a Providência, se deixarmos de lado o acaso, explica a existência, no homem, desta intelecção e, ao mesmo tempo, o fato de que esta intelecção, referida inevitavelmente ao conhecimento abstrato por conceitos, não pode assegurar$\mathrm{se}^{26}$. Pelo sensus communis, o homem participa de uma ordem intelectual que não lhe é determinada, mas que se estende a ele, da mesma forma que ocorre ao sensus communis nos animais não racionais. A intelecção divina, estendida a tudo, atua no homem por dois meios. Primeiro, pela inteligência que lhe é destinada, determinada ao homem. Assim Deus age sobre o homem e pelo homem. Segundo, pela inteligência que o perpassa, pela qual Deus age apenas sobre o homem. Isso, contudo, o homem é capaz de sentir, isto é, sente seus efeitos, mas não conhece segundo um princípio imanente, que pertence apenas ao intelecto divino.

No intelecto criador divino, o conhecimento do outro é tão claro, limpo e penetrante quanto é para nós o cogito ou o princípio de não contradição. Mas, das coisas exteriores, não temos um conhecimento assim com tamanho grau de imanência. $\mathrm{O}$ intelectualismo de Tomás vale como ápice do seu sistema metafísico, como filosofia da intuição pura divina, mas "no homem, a verdade é mais perfeita no juízo, porque somente ali conhece o outro como existente fora de si” $^{27}$. Daí ser possível coadunar a ideia do verdadeiro como assimilação e união, próprias da unidade indissolúvel entre inteligente e inteligível no intelecto divino, e a famosa ideia do verdadeiro como "adequação do intelecto às coisas", quando está em jogo o intelecto humano, com sua debilidade de inteligência. Isso significa, ao mesmo tempo, uma defesa não antropomórfica do intelectualismo ${ }^{28}$.

\footnotetext{
${ }^{26}$ Claro, se a beleza fosse, do ponto de vista da razão final, apenas casual, então teríamos uma estética relativista, sem qualquer preocupação com a universalidade. Mas isso contraria o que de fato o animal racional sente, diante do ente belo. Essa universalidade, portanto, é uma potência.

27 De Veritate 1,3. Citado em ROUSSELOT, 1999, p.45.

${ }^{28}$ Isto marca a diferença entre as filosofias de Tomás e de Hegel, por exemplo, vistas a partir dos problemas deixados pela filosofia de Kant, com os quais começamos este trabalho. Cf. ROUSSELOT, 1999, p.125.
} 
O problema do sensus communis é, neste contexto, o problema da síntese sensível, mas também este problema duplo: o da inteligibilidade de intenções na natureza e nos entes singulares e, ao mesmo tempo, o problema da impossibilidade de traduzir essa inteligibilidade na linguagem do conhecimento humano por conceitos abstratos e múltiplos. A filosofia de Tomás faz justiça a este duplo inteligir, que atinge também a autocompreensão humana. A filosofia não pode provar este sentido comum, nos termos de uma dedução transcendental, pois é um sentido que percebe a si mesmo. Mas pode integrá-lo numa complexa filosofia da mente e da natureza, que seja também filosofia do inteligível contando com as limitações do explicável sem que, por isso, o inteligível deixe de ser inteligível. Ele apenas não pode ser explicado pela inteligência nossa. Certamente é por alguma.

\section{Referências Bibliográficas}

ALLISON, H. (2001) Kant's Theory of Taste. A Reading of the Critique of Aesthetic Judgment. Cambridge: Cambridge University Press.

ARISTÓTELES. (2010) Sobre a Alma. Trad. Ana Maria Lóio. Lisboa: Imprensa Nacional-Casa da Moeda.

AQUINO, Tomás. (1990) Suma Contra os Gentios. V.I. Porto Alegre/Caxias do Sul: Escola Superior de Teologia São Lourenço de Brindês/Livraria Sulina Editora. . (2001) Suma Teológica. I Parte - Questões 1-43. São Paulo: Loyola. . (2002) Suma Teológica. I Parte - Questões 44-119. São Paulo: Loyola. . (2012) Questões Disputadas sobre a Alma. São Paulo: É Realizações. . (2013) Questões Disputadas sobre o Poder de Deus. Campinas: Ecclesiae.

CARVALHO, M. S. (2013) "Introdução". In: AQUINO, Tomás. O ente e a essência. Porto: Edições Afrontamento.

CHESTERTON, G.K. (2004) Saint Thomas Aquinas. The Catholic Primer. Disponível em <www.catholicprimer.org/chesterton/st_thomas.pdf $>$. Acesso em: nov. 2015.

CLEMENS, C. (1972) Chesterton As Seen by His Contemporaries. New York: Gordon Press.

ECO, U. (2014) From the Tree to the Labyrinth. Historical Studies on the Sign and Interpretation. Cambridge/London: Harvard University Press. 
FERREIRA, M. C. "O subjetivismo absoluto". In: (1992) Recepção da Crítica da Raz̃ão Pura: Antologia de Escritos sobre Kant (1786-1844). Lisboa: Fundação Calouste Gulbenkian.

GARDEIL, Henri-Dominique. (2013a) Iniciação à Filosofia de São Tomás de Aquino: introdução, lógica, cosmologia. São Paulo: Paulus.

. (2013b) Iniciação à Filosofia de São Tomás de Aquino: psicologia, metafísica. São Paulo: Paulus.

GRUPILLO, A. (2016) O homem de gosto e o egoísta lógico: uma introdução crítica à estética de Kant. São Paulo: Loyola.

GUYER, P. (1997) Kant and the claims of taste. Cambridge: Cambridge University Press.

KANT, I. (2001) Crítica da Razão Pura. Lisboa: Fundação Calouste Gulbenkian. . (2002) Crítica da Razão Prática. São Paulo: Martins Fontes.

- (1983) Investigação sobre a evidência dos princípios da teologia natural e da moral. Trad. Alberto Reis. In: Textos Pré-críticos. Porto: Rés.

(1968) Kritik der Urteilskraft. In: Immanuel Kants Werke, v.5, AkademieTextausgabe. Berlin: Walter de Gruyter \& Co., 1968. [Critica da Faculdade do Juíro. Rio de Janeiro: Forense Universitária, 1995.]

Lewis \& Short. A Latin-English Lexicon. Disponível em: <http://www.perseus.tufts.edu/hopper/>. Acesso em: out. 2016.

MACMILLAN, C. (1985) Kant's Deduction of Pure Aesthetic Judgments. In: Kant-Studien, n.76, 1985, 43-54.

MOORE, G.E. (1999) Principia Ethica. Lisboa: Fundação Calouste Gulbenkian.

PLÍNIO, o Jovem. Epistolas III. 1,1-2. Disponível em: <http://members.aon.at/latein/Plinius14.htm>. Acesso em: out. 2016.

ROUSSELOT, Pierre. (1999) A Teoria da Inteligência Segundo Tomás de Aquino. São Paulo: Loyola.

SCHELLING, F. (1980) Cartas filosóficas sobre o dogmatismo e o criticismo. São Paulo: Abril Cultural (Coleção Os Pensadores). . (2014) Filosofia della Rivelarione. Milano: Bompiani.

TELLKAMP, J. A. (2012) Vis aestimativa and vis cogitativa in Thomas Aquinas's Commentary on the Sentences. In: The Thomist 76 (2012): 611-40.

VACCARI, U.R. "Introdução”. In: FICHTE, G. (2014) Sobre o espirito e a letra na fillosofia. São Paulo: Humanitas/Imprensa Oficial do Estado de São Paulo. 